\title{
A felicidade em Platão e Aristóteles
}

\author{
Happiness in Plato and Aristotle \\ La felicidad en Platón y Aristóteles
}

José Cândido da Silva Nóbrega

ORCID: https://orcid.org/0000-0002-0976-3763 Universidade Federal de Campina Grande, Brasil E-mail: jcandidosn@uol.com.br

Mônica Barbosa de Sousa Freitas ORCID: https://orcid.org/0000-0001-8073-3359 Universidade Federal de Campina Grande, Brasil

E-mail: mbarbosadesousafreitas@gmail.com

Francisco das Chagas Bezerra Neto ORCID: https://orcid.org/0000-0001-6232-4383 Universidade Federal de Campina Grande, Brasil E-mail: chagasneto237@gmail.com

Auzenir de Oliveira Abrantes Monteiro

ORCID: https://orcid.org/0000-0003-0363-620X Universidade Federal de Campina Grande, Brasil E-mail: auzenirabrantes@gmail.com

Bianca Silva Araujo

ORCID: https://orcid.org/0000-0003-3895-3512 Universidade Federal do Rio Grande do Norte, Brasil E-mail: biapsicologia80@gmail.com

Larissa Tainá Barbosa de Lima

ORCID: https://orcid.org/0000-0002-2070-3622 Universidade Federal do Rio Grande do Norte, Brasil E-mail: larissatainablima@gmail.com

\begin{abstract}
Resumo
O presente manuscrito tem a o desígnio máximo analisar o tema muito sensível e bastante importante para a filosofia: A "Felicidade" em Platão. Nesta esteira, este artigo, através da pesquisa exploratória, de natureza qualitativa, método dedutivo, coleta de dados document bibliográfica, procedeu-se de modo a realizar uma análise minuciosa do arcabouço doutrinário acerca do filósofo Platão, com o intuito de fazer uma abordagem a partir do tratamento apresentado por ele, na análise da situação contida na historieta inicial, a principal questão encontrada foi a que envolve o conceito de felicidade, formulada na pergunta. Trata-se, portanto, de buscar uma resposta clara, coerente e elucidativa a essa questão e que tenha caráter universal, isto é, que se aplique a todos os casos ou pessoas, pois estas são características importantes de uma resposta filosófica. Por fim, salienta-se que a relevância da atividade filosófica em buscar a definição de filosofia, tendo em vista que a relação entre filosofia e felicidade é fundamental, pois felicidade seria a finalidade última da filosofia.
\end{abstract}

Palavras-chave: Filosofia; Felicidade; Virtude; Amizade.

\begin{abstract}
The present manuscript has the maximum purpose of analyzing the very sensitive and very important theme for philosophy: "Felicidade" in Plato. In this vein, this article, through exploratory research, of a qualitative nature, deductive method, collection of bibliographic document data, proceeded in order to carry out a thorough analysis of the doctrinal framework about the philosopher Plato, with the intention of making an approach to From the treatment presented by him, in the analysis of the situation contained in the initial story, the main question found was the one that involves the concept of happiness, formulated in the question. It is, therefore, a search for a clear, coherent and elucidative answer to this question and one that has a universal character, that is, one that applies to all cases or people, as these are important characteristics of a philosophical response. Finally, it is emphasized that the relevance of philosophical activity in seeking the definition of philosophy, bearing in mind that the relationship between philosophy and happiness is fundamental, since happiness would be the ultimate purpose of philosophy.
\end{abstract}

Keywords: Philosophy; Happiness; Virtue; Friendship.

\section{Resumen}

El presente manuscrito tiene el máximo propósito de analizar el tema muy sensible y muy importante para la filosofía: "Felicidade" en Platón. En esta línea, este artículo, a través de una investigación exploratoria, de carácter cualitativo, método deductivo, recolección de datos de documentos bibliográficos, se procedió a realizar un análisis profundo del 
marco doctrinal sobre el filósofo Platón, con el fin de hacer una aproximación a A partir del tratamiento presentado por él, en el análisis de la situación contenida en el relato inicial, la pregunta principal encontrada fue la que involucra el concepto de felicidad, formulado en la pregunta. Se trata, por tanto, de una búsqueda de una respuesta clara, coherente y elucidante a esta pregunta y que tenga un carácter universal, es decir, que se aplique a todos los casos o personas, ya que estas son características importantes de una respuesta filosófica. Finalmente, se destaca la relevancia de la actividad filosófica en la búsqueda de la definición de filosofía, teniendo en cuenta que la relación entre filosofía y felicidad es fundamental, ya que la felicidad sería el fin último de la filosofía.

Palabras clave: Filosofía; Felicidad; Virtud; Amistad.

\section{Introdução}

A atividade filosófica é uma experiência que tem suas peculiaridades. O saber sobre a felicidade não é algo dos dias de hoje. Em si foi objeto de estudo desde os primórdios, e sempre foi algo que inquietou os estudiosos. Essa inquietação também esteve presente em todos os períodos até os dias atuais, esse fato, entre outros. Trata-se de uma maneira de pensar sobre as coisas, que foge à rotina, ao automática. Mesmo assim é acessível a todos. Em sua origem histórica, a relação entre filosofia e felicidade é fundamental, pois felicidade seria a finalidade última da filosofia.

Como se sabe antes mesmo do nascimento da Filosofia na Grécia já havia discursões referentes à tão questionada felicidade, e como ela poderia ser conquistada. Sendo Aristóteles o precursor da história do pensamento ocidental, propomos aqui estudar em contexto histórico-político e sobre tudo em argumento filosófico e cultural do tempo como também refletir e investigar alguns conceitos de autores que assim como o estagirita, procuraram responder e solucionar questões que até então não tinham respostas. E sabedoria para os gregos, não era apenas um grande saber teórico, mas principalmente prática, tendo em vista que buscava atender ao que consideravam o objetivo supremo da vida humana: a felicidade.

O maior discípulo de Sócrates, que efetivamente levou a especulação filosófica adiante de onde a deixara seu mestre, foi Platão (427-347 a.C.), o qual considerava que todas as coisas têm sua função. Assim, como a função do olho é ver e a do ouvido, ouvir, a função da alma é ser virtuosa e justa, de modo que, exercendo a virtude e a justiça, ela obtém a felicidade.

A filosofia apresentava-se como um conhecimento superior que conduzia à vida boa, isto é, que indicava como viver para ser feliz. E o filósofo se reconhecia como aquele que buscava, praticava e ensinava um método, um caminho para a felicidade. Foi a filosofia que rompeu com essa visão pessimista e procurou estabelecer orientações para que o homem procurasse a felicidade.

Demócrito de Abdera julgava que a felicidade era "a medida do prazer e a proporção da vida". Para atingi-la, o homem precisava deixar de lado as ilusões e os desejos e alcançar a serenidade. A filosofia era o instrumento que possibilitava esse processo. (Cervo, 2016, p. 383).

Desse modo, pontua-se que finalidade última é aquela que está por detrás de todas as finalidades mais imediatas e conscientes de uma ação. Geralmente inconsciente, ela é o motivo fundamental de uma conduta. É que, no fundo, conforme acreditam vários filósofos e psicólogos, a intenção última de toda ação ou conduta é "positiva" no sentido de que, consciente ou inconsciente, a pessoa está buscando, por meio dessa ação, trazer, preservar, aumentar seu bem-estar, ou mesmo evitar, acabar com uma infelicidade.

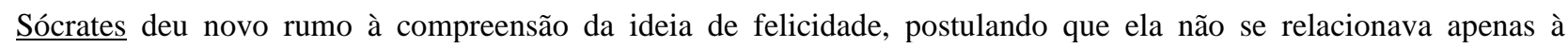
satisfação dos desejos e necessidades do corpo, pois, para ele, o homem não era só o corpo, mas, principalmente, a alma. Assim, a felicidade era o bem da alma que só podia ser atingido por meio de uma conduta virtuosa e justa (Cervo, 2016, p. 383).

Infelizmente, a busca do bem-estar também estar por detrás de muitos comportamentos autodestrutivos, como a dependência de drogas, do álcool e do tabaco, ou antissociais, como a violência e a delinquência, sem falar no simples egoísmo e na falta de consideração pelos demais. Entre os discípulos de Sócrates, Antístenes (445-365 a.C.) acrescentou um toque 
pessoal à ideia de felicidade de seu mestre, considerando que o homem feliz é o homem autossuficiente. A ideia de autossuficiência (que, em grego, se diz "autarquia”,) continuará diretamente vinculada à de felicidade nos anos seguintes.

Assim, afirma que a felicidade é a finalidade última de todos os atos não é dizer que todo e qualquer ato traz felicidade. Como alguém já deve ter experimentado, muitas vezes o que se obtém é o oposto: buscamos felicidade e acabamos conseguindo infelicidade. Por isso é tão importante desenvolver um conhecimento mais crítico sobre o mundo, sobre as coisas, como diz, "nem tudo o que reluz é ouro".

Tendo em vista a relevância do tema proposto, será realizada uma pesquisa exploratória, que tem por objetivo proporcionar uma maior familiaridade com o problema. Sem a perspectiva de esgotamento do tema, tratar-se-á, sobretudo, acerca da busca filosófica do conceito da felicidade consoante Platão. Ademais, se utilizará do método de abordagem dedutivo, uma vez que se buscará os resultados a partir da análise geral até concluir de maneira particular a hipótese. Quanto à natureza da pesquisa, esta será qualitativa, buscar-se-á analisar e interpretar o arcabouço filosófico, como forma de chegar à conclusão da temática da felicidade.

Quanto ao método de procedimento, atribuir-se-á o método monográfico, partindo de um estudo profundo no âmbito da filosofia, que podendo esta pesquisa ser considerada representativa de muitos outros ou mesmo de todos os casos semelhantes. Além do mais, quanto aos procedimentos técnicos, se delineará o presente estudo por meio de pesquisa bibliográfica, tendo em vista que se buscará, através da renomada doutrina da filosofia e periódicos especializados, a solução para conceituar o termo felicidade.

No presente manuscrito, portanto, serão apresentados alguns apontamentos acerca da resposta clara, coerente e elucidativa a essa questão e que tenha caráter universal, isto é, que se aplique a todos os casos ou pessoas sobra a felicidade em Platão.

\section{Desenvolvimento}

O pensamento dos filósofos de outrora, bem como analisar como e pensar com eles pode ser interessante, fecundo e facilita nossa vida pois podemos aproveitar o caminho aberto e depois tomar nosso próprio rumo, sem perder tempo "reinventando a rota". Esses filósofos forjaram algumas visões de mundo bastante diferentes da nossa (ou da sua), mas que ainda fazem algum sentido (ou muito sentido), hoje em dia nem que seja para desafiar nossas próprias visões e fazer com que as aprimoremos.

O objetivo principal deste artigo é avaliar quais os subsídios possíveis que a filosofia Platónica e Aristotélica nos traz acerca da felicidade, para que possa nos proporcionar uma compreensão do que seja realmente a felicidade. Nós não temos tanta segurança sobre o que seja felicidade, no entanto somos a todo momento convocados a tal felicidade, é obvio que qualquer pessoa que pense até mesmo por um instante não toma essa palavra como algo certo, e sim toma-a como uma dúvida: o que é felicidade?

Muitos dizem que felicidade não é uma coisa que está certa, é uma coisa que só podemos falar no nível de pergunta, ou em nível de dúvida. Nesse sentido essa palavra (felicidade), que também é um conceito, ela pode ser usada por nós de um modo muito livre, ou seja, se eu souber o que é felicidade já estarei errado, pois, sobre a felicidade ninguém tem certeza. No entanto esse assunto no sentido de sociedade terá uma ampla interpretação acerca da felicidade. É um elemento de busca constante em nossas vidas, pois a procuramos em coisas, pessoas, objetos e momentos. A felicidade, porém, é uma busca constante, mas não pode ser resumida ao fato de deter riquezas, sucesso, amores e sossego.

É de conhecimento que a felicidade é tida como a ausência da dor, do sofrimento, das angústias etc., mas de fato, o que se define como felicidade? Segundo Aristóteles (384-322 a.C.), a participação do homem na vida divina e no pensamento de Deus, o faz contemplar coisas imutáveis, isto é, quando o homem se desprende das dificuldades cotidianas, dos sofrimentos 
físicos e morais, da fome, da pobreza, da violência, entre outros ele consegue ser feliz, e isso são causas que determinam a felicidade. Dessa forma, cada um de nós pensamos de modo diferente e podemos avaliar essas definições claramente no Livro ética A Nicômaco (2003) que nos diz:

Com efeito, algumas pessoas identificam a felicidade com a virtude, outras com a sabedoria prática, outras com uma espécie de sabedoria filosófica, e outras, ainda, a identificam com tudo isso, ou uma delas, acompanhadas do prazer, ou sem que lhe falte o prazer, e finalmente outras incluem a prosperidade exterior. (Aristóteles, 2003, p. 29).

No entendimento de Platão, o mundo material aquele que percebemos pelos cinco sentidos é enganoso. Nele é instável e por meio dele não pode haver felicidade. Por isso, para esse filósofo, o caminho da felicidade é o do abandono das ilusões dos sentidos em direção ao mundo das ideias, até alcançar o conhecimento supremo da realidade, correspondente a ideia do bem. Para entender a concepção platônica de felicidade, precisamos compreender primeiramente sua doutrina sobre a alma humana, contida na obra A república. Para Platão, o ser humano é essencialmente alma, que é imortal e existe previamente ao corpo. A união da alma com o corpo é ocidental, pois o lugar próprio da alma não é o mundo sensível, e sim o mundo inteligível.

Sim, é possível que exista mesmo uma espécie de trilha que nos conduz de modo reto, quando o raciocínio nos acompanha na busca. E é este então o pensamento que nos guia: durante todo o tempo em que tivermos o corpo, e nossa alma estiver misturada com essa coisa má, jamais possuiremos completamente o objeto de nossos desejos! Ora, este objeto é, como dizíamos, a verdade. Não somente mil e uma confusões nos sãos efetivamente suscitados pelo corpo quando clamam as necessidades da vida, mas ainda somos acometidos pelas doenças - e eis-nos às voltas com novos entraves em nossa caça ao verdadeiro real! O corpo de tal modo nos inunda de amores, paixões, temores, imaginações de toda sorte, enfim, uma infinidade de bagatelas, que por seu intermédio (sim, verdadeiramente é o que se diz) não recebemos na verdade nenhum pensamento sensato; não, nem uma vez sequer! Vede, pelo contrário, o que ele nos dá: nada como o corpo e suas concupiscências para provocar o aparecimento de guerras, dissenções, batalhas; com efeito, na posse de bens é que reside a origem de todas as guerras, e, se somos irresistivelmente impelidos a amontoar bens, fazemo-lo por causa do corpo, de quem somos míseros escravos! Por culpa sua ainda, e por causa de tudo isso, temos a preguiça de filosofar. Mas o cúmulo dos cúmulos está em que, quando conseguimos de seu lado obter alguma tranquilidade, para voltar-nos então ao estudo de um objeto qualquer de reflexão, súbito nossos pensamentos são de novo agitados em todos os sentidos por esse intrujão que nos ensurdece, tonteia e desorganiza, ao ponto de tornar-nos incapazes de conhecer a verdade. [...] Além disso, por todo o tempo que durar nossa vida, estaremos mais próximos do saber, parece-me, quando nos afastarmos o mais possível da sociedade e união com o corpo, salvo em situações de necessidade premente, quando, sobretudo, não estivermos mais contaminados por sua natureza, mas, pelo contrário, nos acharmos puros de seu contato, e assim até o dia em que Deus houver desfeito esses laços. E quando maneira atingirmos a pureza, pois que então teremos sido separados da demência do corpo, deveremos verossimilmente ficar unidos a seres parecidos conosco; e por nós mesmos conheceremos sem mistura alguma tudo o que é. E nisso, provavelmente, é que há de consistir a verdade. Com efeito, é lícito admitir que não seja permitido apossar-se do que é puro, quando não se é puro. (Platão, 1979, pp. 67-68).

Com isso, como bem afirma o trecho acima citado, o homem deve fugir não somente do corpo, raiz do mal, mas também deve fugir do próprio mundo sensível, que em comunhão com o corpo na imperfeição e na maldade, tentam cada vez mais tornar os homens incapazes de encontrar a verdade. E é neste ponto que se localiza toda a moral platônica, pois a melhor maneira de se fugir do corpo e do mundo (do mal) é tornando-se virtuoso, assemelhando o quanto possível a Deus (que é o exemplo mais claro e perfeito de ausência do mal), como assim diz Platão em sua obra Teeteto:

Sim; mas não é possível, Teodoro, nem que os males desapareçam, pois tem de haver sempre alguma coisa contrária ao bem, nem que eles tenham lugar entre os deuses. É uma necessidade que os males circulem entre o gênero humano e sobre este mundo. Por isso devemos tentar fugir o mais depressa possível deste mundo para o outro. Ora, esta fuga consiste em tornarmo-nos, dentro do possível, semelhantes à divindade e sermos semelhantes à divindade é tornarmonos justos e piedosos, com a ajuda da inteligência. (Platão, s/d, p. 96). 
Com isso, pode-se também encontrar dentro de sua metafísica uma explicação para o mal antropológico, como dores, sofrimentos e males físicos, pois como o próprio Platão escreveu no Fédon, "não somente mil e uma confusões nos são efetivamente suscitadas pelo corpo quando clamam as necessidades da vida, mas ainda somos acometidos pelas doenças" (Platão, 1979, p. 67).

Nesse sentido, para Platão, a felicidade é o resultado final de uma vida dedicada a um conhecimento progressivo até se atingir a ideia do bem, o que poderia ser sintetizado na seguinte fórmula: conhecimento = bondade/justiça = felicidade. As três coisas quando ocorrem em sua máxima expressão, andariam sempre juntas, mas com o caminho partindo do conhecimento. Segundo Lopes, a felicidade em Platão depende de uma visão global, que está em relação com outras virtudes:

Os homens procuram a felicidade, no entanto, como condição da própria felicidade, estes não podem cometer injustiças: "o homem e a mulher são felizes quando são bons e virtuosos, infelizes quando são injustos e maus" (PLATÃO, Górgias, 470e). A felicidade reside numa ação de acordo com a sabedoria e a justiça. A injustiça, além de não trazer felicidade ao homem, é o maior dos males: na sua ação, o homem bom deve visar o conceito de justiça (dikaiosyne). A sabedoria, por seu termo, tem um carácter importante para o pensador porquanto o homem bom será o mais inteligente: "um só homem sábio tem mais poderes do que milhares de homens que não o são, é a ele que cabe comandar e aos outros obedecer" (PLATÃO, Górgias, 490a). No entanto aqueles que podem ser chamados os mais poderosos e melhores são inteligentes, mas também corajosos (PLATÃO, Górgias, 491c), logo, o homem bom deverá ser sábio e corajoso. (Lopes, 2014, p. 8).

Aristóteles concordava com Platão que a finalidade última de todos os indivíduos é a felicidade; mas como alcança-

la?

[...] O que é próprio de cada coisa é, por natureza, o que há de melhor e aprazível para ela; e assim, para o homem a vida conforme a razão é a melhor e a mais aprazível, já que razão, mais que qualquer outra coisa, é o homem. Donde se conclui que essa vida é também a mais feliz. (Aristóteles, 2003, p. 190).

Aristóteles afirma que um ser só alcança seu fim quando cumpre a função (ou faculdade) que lhe é própria e o distingue dos demais seres, isto é, sua virtude. A palavra virtude é entendida aqui como aquela propriedade de um ser que ele é mais característica e essencial, cuja aplicação conduz à excelência ou perfeição desse ser. Para Aristóteles, portanto, não basta ter uma virtude (a racionalidade). É preciso praticá-la. O ser humano precisa esforçar-se para realizar aquilo que lhe é dado pela natureza como potência (possibilidade de ser).

Desse modo o filósofo preconizava que, para atingir a felicidade verdadeira, o indivíduo deveria dedicar-se fundamentalmente à vida teórica, no sentido de uma contemplação intelectual, buscando observar beleza e a ordem do cosmo, a autêntica realidade das coisas. E essa forma de atuar deveria manter-se durante a vida inteira: "[...] porquanto uma andorinha não faz verão, nem um dia tão pouco; e da mesma forma um dia, ou um breve espaço de tempo, não faz um homem feliz e virtuoso" (Aristóteles, 2003, p. 16).

Nos dias atuais, podemos observar que existem diversas investigações sobre o que realmente é a felicidade e a que ela está inteiramente ligada segundo as teorias de alguns filósofos e pesquisadores e principalmente na visão Aristotélica. No grego antigo, várias palavras traduziam distintos aspectos da felicidade. A principal delas era eudaimonia, derivada dos termos eu ("bem-disposto") e daimon ("poder divino"). Trata-se da felicidade entendida como bem ou poder concedido pelos deuses. Subentendia-se que, para mantê-la, a pessoa deveria conduzir sua vida de tal maneira a não se indispor com as divindades, para o que era preciso sabedoria. Mesmo assim corria o risco de perder esse bem ou poder se os deuses assim o desejassem, por qualquer motivo arbitrário: "Isso significa que a felicidade era tida como uma espécie de fortuna ou acaso - enfim, um bem instável que dependia tanto da conduta pessoal, como da boa vontade divina" (Estudando História, 2017).

Dessa forma, podemos dizer que, quando agimos de acordo os princípios éticos, encontramos a felicidade com mais facilidade, porém, o que os diversos tipos de mídias passam para as pessoas é que para ser feliz precisamos buscar bens 
matérias a qualquer custo. Vivemos rodeados de regras e dessa forma, precisamos nos comportar mais humanamente diante dos princípios de condutas e normas morais que a contemporaneidade nos oferece.

Vê-se por isso que, a obra eudaimonia de Aristóteles nos orienta como o ser humano pode buscar a plenitude sendo justo e ter uma vida feliz fundamentado nos princípios racionais. Com a análise deste livro, podemos comprovar que o filósofo nos mostra que por meio das nossas virtudes, podemos ter uma vida com total liberdade e assim, encontrar o bem almejado por todos. "A felicidade seria o encontro daquilo que sou capaz de compreender em relação à própria vida que vivo, o encontro do meu pensamento com a minha razão". No entanto cada um pode desenhar sua ideia de felicidade, quando a gente fala sobre a felicidade, no sentido filosófico do termo estamos se referindo sobre a capacidade que a pessoa tem de excogitar essa sensação para si mesma.

\section{Considerações Finais}

Percebe-se, mediante considerações abordadas durante o texto, que atualmente na História da Filosofia verifica-se diferentes apreciações sobre a ética e a felicidade e ao mesmo tempo dificuldades de conceituar por existir várias maneiras e formas de posicionar diante da questão.

Nesta senda, viver em um sentido intenso da própria exuberância criativa que é a vida, e é obvio que uma vida feliz não é uma vida livre de tristeza. Pode ser feliz de diversas maneiras completamente diferente, no entanto, para que a vida possa ser feliz, precisa romper com o preconceito, reconhecendo o lugar de cada um no mundo junto com outras pessoas, tendo a felicidade como meio ético. Assim, cabe ressaltar que a felicidade se encontra no percurso da vida e não no final, pois felicidade não é um estado físico, e sim um sentimento.

Dessa maneira, levando em consideração essa necessidade de assegurar a investigação filosófica, de forma eficaz, a análise minuciosa acerca da felicidade, acreditamos que investigações como esta devem ser prosseguidas. Sendo assim, como sugestão para continuidade de discussões nesse sentido, analisar, à luz da historiografia da filosofia, de que modo as os filósofos atribuíram a definição de felicidade podem ser implementadas com o fito de melhorar o desempenho social da conjuntura societária.

\section{Referências}

Aristóteles. (2003). Ética a Nicômaco. Martin Claret.

Aristóteles. (2002). Política. Martin Claret.

Cervo, A. F. G. (2016). Humanismo histórico: estudo de sua evolução para chegar à felicidade e realização. Saber Humano, Edição especial: Cadernos de ontopsicologia. https://saberhumano.emnuvens.com.br/sh/article/viewFile/128/149.

Cotrim, G., \& Fernandes, M. (2010). Fundamentos da Filosofia. Saraiva.

Estudando História. (2017). Como Viver para ser Feliz? O que disseram os sábios gregos. http://estudandohistorianoblog.blogspot.com/2017/05/como-viverpara-ser-feliz.html.

Givaldo, J. (2012). Como viver para ser feliz. http://josegivaldo.blogspot.com.br/2012/11/como-viver-para-ser-feliz-o-que.html.

Lopes, H. (2014). As Virtudes do Homem Bom: um paralelismo entre Platão e Aristóteles. Covilhã: Universidade da Beira Interior.

Pires, D. B. de S. Felicidade na visão aristotélica. http://www.webartigos.com/artigos/felicidade-na-visao-aristotelica/5793/\#ixzz3Fm87zbbw.

Platão. (1979). Fédon. Tradução Jorge Paleikat e João Cruz Costa: Abril Cultural. Coleção Os Pensadores.

Platão. Teeteto. Tradução Fernando Melro. (2a ed.), Editorial Inquérito, s/d.

Whitehead, A. N. (1978). Process and Reality. An Essay in Cosmology. Free Press. 